\title{
Ganho de seleção no melhoramento genético intrapopulacional do maracujazeiro-amarelo
}

\author{
Willian Krause(1), Regis Santos de Souza(1), Leonarda Grillo Neves ${ }^{(1)}$, Maurecilne Lemes da Silva Carvalho(1), \\ Alexandre Pio Viana ${ }^{(2)}$ e Fábio Gelape Faleiro(3)
}

\begin{abstract}
(1)Universidade do Estado de Mato Grosso, Departamento de Agronomia, Laboratório de Melhoramento de Plantas e Sementes, Rodovia MT 358, Km 07, Jardim Aeroporto, CEP 78300-000 Tangará da Serra, MT. E-mail: krause@unemat.br, regis_agro2008@hotmail.com, leonardaneves@unemat.br, maurecilne@gmail.com (2)Universidade Estadual do Norte Fluminense, Centro de Ciências e Tecnologias Agropecuárias, Laboratório de Melhoramento Genético Vegetal, Avenida Alberto Lamego, № 2.000, Horto, CEP 28015-620 Campos dos Goytacazes, RJ. E-mail: pirapora@uenf.br ${ }^{(3)}$ Embrapa Cerrados, BR 020, Km 18, CEP $73310-970$ Planaltina, DF. E-mail: ffaleiro@cpac.embrapa.br
\end{abstract}

Resumo - O objetivo deste trabalho foi estimar o ganho de seleção associado a características agronômicas de importância no melhoramento intrapopulacional do maracujazeiro-amarelo. $\mathrm{O}$ experimento foi realizado em campo, no Município de Terra Nova do Norte, MT, com a avaliação de 111 famílias de irmãos completos (FIC) e seis cultivares comerciais, utilizadas como testemunhas. Utilizou-se o delineamento de blocos ao acaso, com três repetições e quatro plantas por parcela. Foram avaliadas as seguintes características: produtividade, comprimento, diâmetro e peso médio dos frutos, percentagem e peso de polpa, espessura de casca e teor de sólidos solúveis. Para verificar a existência de variabilidade genética entre os genótipos, estimaram-se os parâmetros genéticos da população com base na média das famílias. Os 30 genótipos com o menor valor da soma de postos, de acordo com o índice de seleção de Mulamba \& Mock, foram selecionados para estimar os ganhos genéticos. Observaram-se altos valores médios para as características e parâmetros genéticos avaliados nas 26 FIC e nas quatro testemunhas selecionadas. O uso do índice de seleção proporciona ganhos genéticos positivos em produtividade, percentagem e peso de polpa, comprimento, diâmetro e peso de frutos, e espessura de casca.

Termos para indexação: Passiflora edulis, correlação entre caracteres, herdabilidade, índice de seleção, seleção recorrente.

\section{Selection gain in the intrapopulation genetic breeding of yellow passion fruit}

\begin{abstract}
The objective of this work was to estimate the selection gain associated to traits of agronomic importance, in the intrapopulation genetic breeding of yellow passion fruit. The experiment was carried out in the field, in Terra Nova do Norte, MT, Brazil, by evaluating 111 full-sib families (FSF) and six commercial cultivars, used as controls. The experimental design was a randomized complete block, with three replicates and four plants per plot. The following traits were evaluated: productivity, fruit length, diameter and weight, pulp percentage and weight, skin thickness, and soluble solid content. In order to determine the genetic variability between genotypes, the population's genetic parameters were estimated based on the means of the families. The 30 genotypes with the lowest sum of ranks, according to Mulamba \& Mock's selection index, were selected to estimate genetic gains. High mean values were observed for the evaluated characteristics and genetic parameters in the 26 FSF and in the four controls selected. The selection index provides positive genetic gains as to: productivity, pulp percentage and weight, fruit length, diameter and weight, and skin thickness.
\end{abstract}

Index terms: Passiflora edulis, correlation between traits, heritability, selection index, recurrent selection.

\section{Introdução}

O Brasil é o maior produtor mundial de maracujá (Passiflora edulis Sims), com produção em torno de 615 mil toneladas por ano. No entanto, a produtividade média do país é de apenas $13,9 \mathrm{Mg} \mathrm{ha}^{-1}$ por ano (Agrianual, 2010), considerada baixa quando comparada aos valores de $30-45 \mathrm{Mg} \mathrm{ha}^{-1}$ por ano alcançados em pesquisas.

O melhoramento genético do maracujazeiro trouxe avanços significativos em relação à produtividade, qualidade de frutos, e resistência e tolerância às doenças e pragas importantes da cultura (Gonçalves et al., 2007; Santos et al., 2008). Entretanto, um dos 
fatores responsáveis pela baixa produtividade da cultura do maracujazeiro é a utilização de cultivares inadequadas às condições edafoclimáticas da região de plantio (Junqueira et al., 1999). Há várias cultivares comerciais de maracujá disponíveis no mercado, tais como: híbridos intravarietais da série 270, desenvolvidos pelo Instituto Agronômico (IAC) de Campinas; híbridos BRS Sol do Cerrado, BRS Gigante Amarelo e BRS Ouro Vermelho, lançados pela Embrapa; e cultivares da série FB da Flora Brasil. Porém, como nenhuma dessas cultivares foi desenvolvida para o Estado de Mato Grosso, elas podem não ser totalmente adaptadas às condições de plantio no estado, em razão da interação genótipo x ambiente.

A seleção recorrente intrapopulacional é um processo cíclico de melhoramento que envolve, basicamente, a obtenção de progênies e a avaliação e o intercruzamento dos melhores indivíduos para formar a população melhorada. Por meio desse tipo de seleção, espera-se aumentar a frequência de alelos favoráveis e, consequentemente, melhorar a expressão fenotípica do caráter sob seleção, além de conservar a variabilidade genética para comportar ganhos genéticos nos ciclos seguintes (Hallauer \& Darrah, 1985). Uma das etapas desse método é a seleção. O progresso genético depende basicamente da magnitude da variabilidade genética, que é intrínseca à cada população de trabalho.

O uso de índices de seleção para múltiplos caracteres possibilita a obtenção de genótipos mais produtivos e adaptados, pela reunião de diversos atributos favoráveis. De forma geral, um índice de seleção deve permitir a classificação correta dos genótipos e considerar diversos caracteres simultaneamente (Cruz et al., 2004). No melhoramento do maracujazeiro-amarelo, diversos trabalhos têm utilizado índices de seleção (Negreiros et al., 2004; Gonçalves et al., 2007; Oliveira et al., 2008; Silva et al., 2009). Entre os índices, o de Mulamba \& Mock tem sido comumente recomendado (Gonçalves et al., 2007; Silva et al., 2009).

O objetivo deste trabalho foi estimar o ganho de seleção, associado a características agronômicas de importância, no melhoramento intrapopulacional do maracujazeiro-amarelo.

\section{Material e Métodos}

A partir da população UENF-MA ${ }_{1}$, desenvolvida pelo programa de melhoramento genético do maracujazeiro-amarelo da Universidade Estadual Norte Fluminense Darcy Ribeiro, foram obtidas 111 famílias de irmãos completos (FIC) (Silva et al., 2009). Estas FIC, juntamente com seis testemunhas, representadas pelas cultivares comerciais BRS Sol do Cerrado, BRS Gigante Amarelo, BRS Ouro Vermelho, FB 200, IAC 275 e IAC 277, foram avaliadas em delineamento de blocos ao acaso, com três repetições e quatro plantas por parcela.

O experimento foi conduzido em condições de campo, na área experimental da Cooperativa Agropecuária Mista Terra Nova, situada no Município de Terra Nova do Norte, MT $\left(10^{\circ} 34^{\prime} \mathrm{S}\right.$ e $55^{\circ} 07^{\prime} \mathrm{W}$, a $310 \mathrm{~m}$ de altitude). O plantio foi realizado em janeiro de 2009, no espaçamento de $3 \times 3 \mathrm{~m}$, para possibilitar o tráfego de máquinas dentro da área experimental. O sistema de condução foi o de espaldeira vertical, com mourões de $2,5 \mathrm{~m}$, espaçados a $6 \mathrm{~m}$, e com um fio de arame liso número 12, a partir de $1,8 \mathrm{~m}$ do solo.

Os frutos foram colhidos duas vezes por semana. As avaliações foram feitas em 20 frutos, coletados ao longo de todo o período da colheita. Foram avaliadas as seguintes características: produtividade (Prod), em kg ha-1; comprimento (CF) e diâmetro de frutos (DF), em milímetros; espessura de casca (EC), em milímetros, determinada por meio de medição em quatro pontos na porção mediana dos frutos, com utilização de paquímetro digital; peso de fruto $(\mathrm{PF})$, em gramas; percentagem de polpa (PP), determinada após a pesagem da polpa (sementes com arilo), por meio da divisão do peso de polpa pelo peso total do fruto; quantidade de polpa por hectare (PEP), obtida por meio da multiplicação da produtividade por PP; e teor de sólidos solúveis (SS), obtido por refratometria, com uso de refratômetro digital portátil, modelo RTD-45 (Instrutherm, São Paulo, SP), com escala de $0-45^{\circ}$ Brix. No caso de SS, as leituras foram realizadas em amostras de suco da polpa de cinco frutos, extraído por prensagem manual e filtragem em tela de nylon.

Para verificar a existência de variabilidade genética entre as FIC, foi realizada análise de 
variância e foram estimados os parâmetros genéticos da população, com base nas médias das famílias. Adotou-se o modelo estatístico

$$
\mathrm{Y}_{\mathrm{ij}}=\mathrm{m}+\mathrm{T}_{\mathrm{i}}+\mathrm{b}_{\mathrm{j}}+\varepsilon_{\mathrm{ij}},
$$

em que: $Y_{\mathrm{ij}}$ é o valor observado no i-ésimo tratamento, no j-ésimo bloco; $\mathrm{m}$ é a média geral do ensaio; $\mathrm{T}_{\mathrm{i}}$ é o efeito do i-ésimo tratamento; $b_{\mathrm{j}}$ é o efeito do j-ésimo bloco; e $\varepsilon_{\mathrm{ij}}$ é o efeito do erro aleatório (Cruz \& Carneiro, 2003). Para $i=1,2, \ldots$ g, obteve-se o efeito aleatório das FIC, e para i $=\mathrm{g}+1, \mathrm{~g}+2, \ldots \mathrm{g}+\mathrm{t}$, o efeito fixo de testemunhas. As análises foram realizadas com uso do programa Genes (Cruz, 2006a).

Para a estimação dos ganhos genéticos preditos, utilizou-se o índice de seleção de Mulamba \& Mock (1978), identificado como o mais adequado, com maiores ganhos preditos para a avaliação de FIC em maracujá (Gonçalves et al., 2007; Santos et al., 2008). Esse índice consiste em classificar as progênies, em relação a cada uma das características, em ordem favorável ao melhoramento. As ordens referentes às características são somadas para cada progênie, obtendo-se a soma de postos. Assim, quanto menor for o valor obtido na soma de postos, melhor é o desempenho da progênie, em relação às várias características avaliadas (Cruz et al., 2004). Os 30 genótipos com o menor valor da soma de postos foram selecionados, e o ganho de seleção foi estimado pela expressão $\mathrm{GS}+\left(\overline{\mathrm{X}}_{\mathrm{S}}-\overline{\mathrm{X}}_{\mathrm{O}}\right) \mathrm{h}^{2}$, em que: GS é o ganho de seleção; $\bar{X}_{S}$ é a média dos 30 genótipos selecionados; $\overline{\mathrm{X}}_{\mathrm{O}}$ é a média dos 117 genótipos avaliados; e $\mathrm{h}^{2}$ é a herdabilidade com base na média das FIC.
A predição dos ganhos foi realizada com base no acréscimo em todas as características avaliadas, exceto para a característica EC. Para esses procedimentos, utilizou-se o programa Genes (Cruz, 2006b). As médias dos genótipos selecionados para cada característica foram comparadas pelo teste de Scott-Knott (1974), a 5\% de probabilidade.

\section{Resultados e Discussão}

Houve diferença significativa entre os genótipos, para todas as características avaliadas. Como a análise foi realizada no delineamento de blocos ao acaso, com testemunhas adicionais, a fonte de variação genótipos foi decomposta em progênies e testemunhas. Para progênies, observou-se diferença significativa, para todas as características avaliadas, quanto à fonte de variação FIC. Essa diferença significativa entre as FIC indica haver variabilidade genética e potencial para realização da seleção. Quanto à fonte de variação testemunhas, houve diferença significativa apenas para as características PP, CF e EC.

As menores estimativas de herdabilidade foram observadas para as características DF e SS, com valores de 31,76 e $36,58 \%$, respectivamente (Tabela 1). Silva etal.(2009) obtiveram herdabilidade de $83,5 \%$ para a característica DF. No entanto, os valores de herdabilidade são intrínsecos à cada população. As características Prod, PF, EC, PP, PEP e $\mathrm{CF}$ apresentaram estimativas de herdabilidade relativamente altas: 52,59, 50,58, 52,12, 55,71, 52,77 e $58,05 \%$, respectivamente. Esse resultado é

Tabela 1. Análise de variância e estimativas de herdabilidade $\left(\mathrm{h}^{2}\right)$ para as características produtividade (Prod), percentagem de polpa (PP), peso de polpa (PEP), teor de sólidos solúveis (SS), peso de fruto (PF), comprimento de frutos (CF), diâmetro de frutos (DF) e espessura de casca (EC), em 111 famílias de irmãos completos (FIC) e seis testemunhas comerciais (Te) de maracujazeiro amarelo.

\begin{tabular}{|c|c|c|c|c|c|c|c|c|c|}
\hline \multirow[t]{2}{*}{ Fonte de variação } & \multirow[t]{2}{*}{ Gl } & \multicolumn{8}{|c|}{ Quadrados médios } \\
\hline & & Prod & PP & PEP & SS & PF & $\mathrm{CF}$ & DF & $\mathrm{EC}$ \\
\hline Blocos & 2 & 178.641 .765 & 263 & 15.983 .653 & 16,76 & 1.503 & 281 & 141 & 0,56 \\
\hline Genótipos & 116 & $64.933 .230 * *$ & $94 * *$ & $8.663 .995 * *$ & $6,86 * *$ & $1.550 * *$ & $84 * *$ & $81 * *$ & $1,67 * *$ \\
\hline FIC & 110 & $63.645 .966 * *$ & $82 * *$ & $8.216 .713^{* *}$ & $6,80 * *$ & $1.536^{* *}$ & $77 * *$ & $80 * *$ & $1,61 * *$ \\
\hline $\mathrm{Te}$ & 5 & $43.641 .315^{\mathrm{ns}}$ & $287 * *$ & $2.265 .915^{\mathrm{ns}}$ & $0,36^{\text {ns }}$ & $1.528^{\mathrm{ns}}$ & $139 * *$ & $100^{\text {ns }}$ & $3,08 * *$ \\
\hline FIC $\times \mathrm{Te}$ & 1 & $312.991 .861 * *$ & $525 * *$ & $89.855 .456 * *$ & $46,66^{* *}$ & $3.198 *$ & $566 * *$ & $102^{\mathrm{ns}}$ & $0,74^{\mathrm{ns}}$ \\
\hline Resíduo & 232 & 30.176 .463 & 36 & 3.880 .341 & 4,31 & 759 & 32 & 55 & 0,77 \\
\hline $\mathrm{h}^{2}(\%)$ & - & 52,59 & 55,71 & 52,77 & 36,58 & 50,58 & 58,05 & 31,76 & 52,12 \\
\hline
\end{tabular}

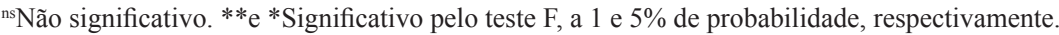


indicativo de boa possibilidade de ganho genético com a seleção.

A estimação da herdabilidade tem sido realizada em vários trabalhos com o maracujazeiro. Moraes et al. (2005) estimaram parâmetros genéticos e fenotípicos para caracteres relacionados à produção e à qualidade de frutos. Observouse ampla variabilidade genética, o que pode ser comprovado pelas altas estimativas dos coeficientes de herdabilidade, que variaram de 52,6 a $83,2 \%$. Oliveira et al. (2008) encontraram valores de herdabilidade de médias de progênies de 11 a 57\%. Porém, as estimativas variaram de 3 a $38 \%$, para herdabilidade dentro de progênies, o que indica que a seleção entre progênies seria a estratégia mais viável para o melhoramento. Gonçalves et al. (2007) avaliaram a melhor alternativa de seleção para uma população de maracujazeiro-amarelo estruturado no delineamento genético I, proposto por Comstock \& Robinson (1948). Segundo esses autores, os coeficientes de herdabilidade mais elevados foram obtidos para famílias de machos, com valores de 59,97 a 90,49\%. Cabe ressaltar que a seleção baseada na média de machos é praticada entre os valores médios obtidos para cada família de macho, com progênies provenientes de fêmeas polinizadas por um mesmo indivíduo. Silva et al. (2009), ao avaliar 26 famílias de meios-irmãos, obtiveram coeficientes de herdabilidade de 36,9 a $83,5 \%$, para características agronômicas.

Apesar de terem apresentado magnitudes medianas, as estimativas de herdabilidade para a população avaliada no presente trabalho proporcionaram ótimos ganhos genéticos (Tabela 2). Além disso, no caso da seleção recorrente intrapopulacional, o objetivo é aumentar gradativamente a frequência dos alelos desejáveis para características quantitativas, por meio dos repetidos ciclos de seleção e recombinação (Hallauer, 1992).

As estimativas dos coeficientes de correlação fenotípica e genotípica, em médias de genótipos, entre PF $x$ Prod, PEP, DF, CF e EC, foram positivas e de alta magnitude (Tabela 3 ). Assim, ao aplicar a seleção para o aumento de uma dessas características, espera-se resposta correlacionada às outras, o que constitui aspecto vantajoso, uma vez que o sentido da seleção é o mesmo para esses caracteres (Paula et al., 2002). Embora os maiores frutos também tenham apresentado maior peso de polpa, a ausência de correlação entre PF x PP pode ser explicada pela covariância existente entre essas características, já que a variação em PF normalmente levará à variação em $\mathrm{PP}$. O coeficiente de correlação fenotípica e genotípica entre Prod $\mathrm{x}$ SS foi negativo, o que indica que a seleção, quanto a uma dessas características, pode resultar em alta resposta correlacionada negativa na outra, o que constitui problema, pois, além do aumento em produtividade, espera-se, também, aumento no teor de SS. Contudo, quando se efetuou a seleção, no presente trabalho, a redução de SS foi apenas de $0,42 \%$ (Tabela 2).

Quanto aos caracteres não correlacionados, a seleção pode ser feita de forma independente. Observou-se tendência de os coeficientes de correlação fenotípica superarem os de correlação genotípica, o que mostra que os fatores genéticos foram menos importantes que os de ambiente, na expressão desses caracteres.

A seleção com base em uma única característica é inadequada, pois, apesar de conduzir a um produto final superior em relação à esta característica, pode levar a desempenhos não satisfatórios para as demais (Cruz et al., 2004). Uma forma de se aumentar o êxito com a seleção é o uso da seleção simultânea quanto a várias características, por meio da utilização de índices de seleção.

Tabela 2. Média original (MO), média dos genótipos selecionados (MS) e estimativas de ganhos genéticos preditos (GS), pela relação simultânea quanto às características produtividade (Prod), percentagem de polpa (PP), peso de polpa (PEP), teor de sólidos solúveis (SS), peso de fruto $(\mathrm{PF})$, comprimento de frutos $(\mathrm{CF})$, diâmetro de frutos (DF) e espessura de casca (EC), em 111 famílias de irmãos completos e seis testemunhas de maracujazeiro amarelo.

\begin{tabular}{lcccc}
\hline Caráter & MO & MS & GS & GS $(\%)$ \\
\hline Prod $\left(\mathrm{kg} \mathrm{ha}^{-1}\right)$ & $14.651,61$ & $19.504,1$ & $2.638,36$ & 18,01 \\
PP $(\%)$ & 33,12 & 35,1 & 0,90 & 2,73 \\
PEP $\left(\mathrm{kg} \mathrm{ha}^{-1}\right)$ & $4.810,82$ & $6.766,0$ & $1.029,96$ & 21,41 \\
SS $\left({ }^{\circ}\right.$ Brix $)$ & 14,57 & 14,6 & $-0,06$ & $-0,42$ \\
PF $(\mathrm{g})$ & 160,20 & 178,0 & 9,45 & 5,90 \\
CF $(\mathrm{mm})$ & 77,40 & 80,1 & 2,12 & 2,74 \\
DF $(\mathrm{mm})$ & 74,23 & 77,1 & 1,05 & 1,41 \\
EC $(\mathrm{mm})$ & 7,00 & 7,21 & 0,12 & 1,73 \\
\hline Total & - & - & - & 53,51 \\
\hline
\end{tabular}


Dos 117 genótipos avaliados, foram selecionados 30 , sendo 26 FIC e quatro testemunhas ('BRS Sol do Cerrado', 'BRS Gigante Amarelo', 'BRS Ouro Vermelho' e 'FB 200'). O material genético destas FIC foi proveniente de um total de 21 genótipos, coletados em populações comerciais de maracujá-amarelo na região norte e noroeste do Estado do Rio de Janeiro (Viana et al., 2003, 2006). Estes autores observaram que esses genótipos apresentavam baixa variabilidade genética, o que indica que variabilidade adicional deveria ser introduzida nas populações, para que se pudesse obter bons índices e ganhos satisfatórios. Portanto, a introdução das quatro cultivares comerciais entre os genótipos selecionados, para serem recombinados durante a seleção recorrente, foi vantajosa para formar a população. Este fato torna o processo dinâmico e permite a capitalização do progresso genético obtido nos diversos programas de melhoramento (Ramalho et al., 2005).

Os maiores ganhos genéticos preditos foram de $21,41 \%$, para a característica PEP, o que correspondeu a $1.029,96 \mathrm{~kg} \mathrm{ha}^{-1}$ de polpa, e de $18,01 \%$, para Prod, o que correspondeu a $2.638,36 \mathrm{~kg} \mathrm{ha}^{-1}$ (Tabela 3). Para as demais características, os ganhos foram menores; contudo, úteis na aplicação da seleção recorrente, com $2,73 \%$ para PP, $1,41 \%$ para DF, $1,73 \%$ para $\mathrm{EC}, 2,74 \%$ para $\mathrm{CF}$ e $5,90 \%$ para $\mathrm{PF}$. Ao analisar diversos índices de seleção em uma população de maracujá-amarelo estruturada no delineamento I, Gonçalves et al. (2007) obtiveram o melhor ganho genotípico predito ao utilizar o índice de Mulamba \& Mock (1978). Os ganhos observados por esses autores foram de $15,85 \%$ para número de frutos por planta, $0,82 \%$ para peso de frutos, $0,35 \%$ para comprimento de frutos, $0,77 \%$ para largura de frutos, $1,55 \%$ para espessura de casca e $-2,80 \%$ para número de dias até a antese. Santos et al. (2008) avaliaram o vigor e a resistência à verrugose e obtiveram ganhos genéticos de aproximadamente $10 \%$, para ambas as características, com uso do mesmo índice de seleção. Já Silva et al. (2009), ao utilizar o índice de Mulamba \& Mock (1978) em 26 progênies de meios-irmãos, observaram ganhos genéticos preditos de $3,18 \%$ para peso de fruto, $0,47 \%$ para comprimento de fruto, $1,36 \%$ para largura de fruto e $0,65 \%$ para espessura de casca. Oliveira et al. (2008), ao avaliar 16 progênies de meios-irmãos, obtiveram ganhos positivos em todos os caracteres pela seleção direta, que variaram de $2,5 \%$, para formato do fruto, a $27,58 \%$, para número de frutos. Para a característica produtividade de polpa, estes autores observaram ganho de $11,33 \%$.

As FIC apresentaram elevado desempenho agronômico para a maioria das características avaliadas (Tabela 4). Para Prod, todas as 26 FIC selecionadas apresentaram médias superiores à média geral, e 13 apresentaram médias superiores a das testemunhas. Para PEP, que é outra característica de grande importância, as 26 FIC selecionadas também ficaram acima da média geral, e nove foram superiores às testemunhas. Assim, os resultados do presente trabalho são indicativos de que a inclusão de variedade na população, por meio do uso de variedades comerciais na seleção recorrente, apresenta alto potencial em proporcionar ganhos genéticos consistentes e equilibrados nas diversas características avaliadas.

Tabela 3. Estimativas de correlação fenotípica ${ }^{(1)}$ e genotípica $^{(2)}$, em médias determinadas em 111 famílias de irmãos completos e seis testemunhas de maracujazeiro amarelo, quanto às características produtividade (Prod), percentagem de polpa (PP), peso de polpa (PEP), teor de sólidos solúveis (SS), peso de fruto (PF), comprimento de frutos (CF), diâmetro de frutos (DF) e espessura de casca (EC).

\begin{tabular}{|c|c|c|c|c|c|c|c|c|}
\hline Caráter & Prod & PP & PEP & SS & $\mathrm{PF}$ & DF & $\mathrm{CF}$ & $\mathrm{EC}$ \\
\hline Prod & & $-0,068$ & $0,892 * *$ & $-0,232 *$ & $0,338 * *$ & 0,233 & $0,362 * *$ & 0,298* \\
\hline PP & $-0,062$ & & $0,357 * *$ & 0,212 & 0,008 & 0,055 & $-0,104$ & $-0,222$ \\
\hline PEP & $0,888 * *$ & 0,388 & & $-0,138$ & $0,325^{* *}$ & 0,213 & $0,297^{*}$ & 0,130 \\
\hline SS & $-0,558 *$ & 0,290 & $-0,405$ & & 0,114 & 0,075 & $-0,016$ & 0,014 \\
\hline PF & 0,475 & 0,138 & $0,506^{*}$ & 0,301 & & $0,479 * *$ & $0,580 * *$ & $0,399 * *$ \\
\hline DF & 0,102 & 0,230 & 0,418 & 0,199 & $0,779^{*}$ & & $0,575 * *$ & 0,117 \\
\hline $\mathrm{CF}$ & $0,548 *$ & $-0,091$ & $0,470^{*}$ & $-0,031$ & $0,811 * *$ & $0,629 *$ & & 0,215 \\
\hline $\mathrm{EC}$ & 0,480 & $-0,134$ & 0,295 & $-0,018$ & $0,637^{*}$ & 0,119 & 0,331 & \\
\hline
\end{tabular}

${ }^{(1)}$ Acima da diagonal; (2)Abaixo da diagonal;** e *Significativo a 1 e $5 \%$ de probabilidade, respectivamente, pelo método de "bootstrap", com 5 mil simulações. 
Tabela 4. Médias dos 30 genótipos selecionados para compor o próximo ciclo de seleção recorrente intrapopulacional, quanto às características produtividade (Prod), percentagem de polpa (PP), peso de polpa (PEP), teor de sólidos solúveis (SS), peso de fruto (PF), comprimento de frutos (CF), diâmetro de frutos (DF) e espessura de casca (EC) ${ }^{(1)}$.

\begin{tabular}{|c|c|c|c|c|c|c|c|c|}
\hline \multirow[t]{2}{*}{$\overline{\text { Genótipo }^{(2)}}$} & Prod & PEP & \multirow{2}{*}{$\begin{array}{l}\mathrm{PP} \\
(\%)\end{array}$} & \multirow{2}{*}{$\begin{array}{c}\text { SS } \\
\left({ }^{\circ} \mathrm{Brix}\right)\end{array}$} & \multirow{2}{*}{$\begin{array}{l}\mathrm{PF} \\
(\mathrm{g})\end{array}$} & $\mathrm{CF}$ & $\mathrm{DF}$ & \multirow{3}{*}{$\begin{array}{c}\text { EC } \\
7,83 a\end{array}$} \\
\hline & \multicolumn{2}{|c|}{---------- $\left(\mathrm{kg} \mathrm{ha}^{-1}\right)$--------- } & & & & \multirow{2}{*}{$\begin{array}{r}-- \\
83,5 a\end{array}$} & \multirow{2}{*}{$\frac{(\mathrm{mm})-}{77,5 \mathrm{~b}}$} & \\
\hline 1 & $16.927,8 \mathrm{a}$ & $5.185,9 \mathrm{a}$ & $31,7 \mathrm{a}$ & $14,9 \mathrm{a}$ & $188,5 \mathrm{a}$ & & & \\
\hline 2 & $23.323,2 \mathrm{a}$ & $8.836,4 \mathrm{a}$ & $39,2 \mathrm{a}$ & $14,9 \mathrm{a}$ & $192,3 a$ & $84,6 \mathrm{a}$ & $79,3 \mathrm{a}$ & $6,43 b$ \\
\hline 3 & $18.136,1 \mathrm{a}$ & $7.513,0 \mathrm{a}$ & $41,7 \mathrm{a}$ & $14,9 \mathrm{a}$ & $209,1 \mathrm{a}$ & $78,3 b$ & $76,1 \mathrm{~b}$ & $7,57 \mathrm{a}$ \\
\hline 4 & $16.107,9 \mathrm{a}$ & $6.084,9 \mathrm{a}$ & $38,5 \mathrm{a}$ & $13,9 b$ & $159,8 \mathrm{a}$ & $74,7 \mathrm{~b}$ & $75,6 \mathrm{~b}$ & $5,93 \mathrm{~b}$ \\
\hline 5 & $18.713,0 \mathrm{a}$ & $6.416,9 \mathrm{a}$ & $35,4 \mathrm{a}$ & $13,5 b$ & $197,2 \mathrm{a}$ & $82,8 \mathrm{a}$ & $80,3 \mathrm{a}$ & $8,17 \mathrm{a}$ \\
\hline 6 & $25.793,1 \mathrm{a}$ & $8.210,0 \mathrm{a}$ & $31,9 \mathrm{a}$ & $12,6 \mathrm{~b}$ & $175,1 \mathrm{a}$ & $77,9 \mathrm{~b}$ & $74,4 \mathrm{~b}$ & $7,47 \mathrm{a}$ \\
\hline 7 & $14.684,3 \mathrm{a}$ & $6.450,5 \mathrm{a}$ & $42,0 \mathrm{a}$ & $15,2 \mathrm{a}$ & $159,3 \mathrm{a}$ & $74,7 \mathrm{~b}$ & $76,0 \mathrm{~b}$ & $5,93 \mathrm{~b}$ \\
\hline 8 & $15.413,9 \mathrm{a}$ & $5.702,2 \mathrm{a}$ & $37,1 \mathrm{a}$ & $13,4 b$ & $184,3 \mathrm{a}$ & $81,3 \mathrm{a}$ & $79,3 \mathrm{a}$ & $7,40 \mathrm{a}$ \\
\hline 9 & $17.362,9 \mathrm{a}$ & $5.749,7 \mathrm{a}$ & $32,9 \mathrm{a}$ & $15,2 \mathrm{a}$ & $179,7 \mathrm{a}$ & $84,8 \mathrm{a}$ & $76,1 \mathrm{~b}$ & $7,50 \mathrm{a}$ \\
\hline 10 & $18.977,3 \mathrm{a}$ & $6.244,6 \mathrm{a}$ & $32,8 \mathrm{a}$ & $15,0 \mathrm{a}$ & $201,7 \mathrm{a}$ & $83,9 \mathrm{a}$ & $78,5 \mathrm{a}$ & $7,53 \mathrm{a}$ \\
\hline 11 & $16.869,4 \mathrm{a}$ & $6.160,8 \mathrm{a}$ & $36,3 \mathrm{a}$ & $14,5 \mathrm{a}$ & $158,0 \mathrm{a}$ & $77,1 \mathrm{~b}$ & $77,1 \mathrm{~b}$ & $7,80 \mathrm{a}$ \\
\hline 12 & $20.267,6 \mathrm{a}$ & $6.985,6 \mathrm{a}$ & $35,9 \mathrm{a}$ & $14,4 \mathrm{a}$ & $172,3 a$ & $79,5 b$ & $78,8 \mathrm{a}$ & $7,03 a$ \\
\hline 13 & $26.133,8 \mathrm{a}$ & $7.954,2 \mathrm{a}$ & $30,4 \mathrm{a}$ & $14,7 \mathrm{a}$ & $195,9 \mathrm{a}$ & $79,8 \mathrm{~b}$ & $75,9 \mathrm{~b}$ & $9,23 \mathrm{a}$ \\
\hline 14 & $21.166,7 \mathrm{a}$ & $7.782,8 \mathrm{a}$ & $36,1 \mathrm{a}$ & $15,0 \mathrm{a}$ & $176,4 \mathrm{a}$ & $84,6 \mathrm{a}$ & $75,8 \mathrm{~b}$ & $6,63 b$ \\
\hline 15 & $30.459,5 \mathrm{a}$ & $11.471,1 \mathrm{a}$ & $37,7 \mathrm{a}$ & $13,8 b$ & $182,3 a$ & $83,3 \mathrm{a}$ & $76,4 \mathrm{~b}$ & $7,27 \mathrm{a}$ \\
\hline 16 & $17.925,9 \mathrm{a}$ & $6.350,9 \mathrm{a}$ & $35,5 \mathrm{a}$ & $15,4 \mathrm{a}$ & $188,1 \mathrm{a}$ & $83,9 \mathrm{a}$ & $79,7 \mathrm{a}$ & $6,83 b$ \\
\hline 17 & $16.151,8 \mathrm{a}$ & $6.607,2 \mathrm{a}$ & $40,9 \mathrm{a}$ & $16,1 \mathrm{a}$ & $160,8 \mathrm{a}$ & $72,0 \mathrm{~b}$ & $72,2 b$ & $6,10 \mathrm{~b}$ \\
\hline 18 & $16.213,0 \mathrm{a}$ & $5.431,6 \mathrm{a}$ & $33,3 \mathrm{a}$ & $14,5 \mathrm{a}$ & $152,9 \mathrm{a}$ & $81,8 \mathrm{a}$ & $78,3 \mathrm{a}$ & $5,93 \mathrm{~b}$ \\
\hline 19 & $19.780,6 \mathrm{a}$ & $7.536,2 \mathrm{a}$ & $38,1 \mathrm{a}$ & $15,3 \mathrm{a}$ & $145,6 \mathrm{a}$ & $74,9 \mathrm{~b}$ & $72,7 \mathrm{~b}$ & $7,10 \mathrm{a}$ \\
\hline 20 & $21.738,0 \mathrm{a}$ & $6.713,7 \mathrm{a}$ & $34,3 \mathrm{a}$ & $13,2 b$ & $169,3 \mathrm{a}$ & $79,4 \mathrm{~b}$ & $74,3 \mathrm{~b}$ & $8,10 \mathrm{a}$ \\
\hline 21 & $15.774,1 \mathrm{a}$ & $5.588,8 \mathrm{a}$ & $35,1 \mathrm{a}$ & $15,1 \mathrm{a}$ & $159,2 \mathrm{a}$ & $75,1 \mathrm{~b}$ & $79,3 \mathrm{a}$ & $5,53 \mathrm{~b}$ \\
\hline 22 & $17.764,4 \mathrm{a}$ & $6.039,6 \mathrm{a}$ & $33,9 \mathrm{a}$ & $14,7 \mathrm{a}$ & $205,1 \mathrm{a}$ & $77,1 \mathrm{~b}$ & $74,2 \mathrm{~b}$ & $8,47 \mathrm{a}$ \\
\hline 23 & $19.888,9 \mathrm{a}$ & $7.167,9 \mathrm{a}$ & $34,4 \mathrm{a}$ & $13,0 \mathrm{~b}$ & $148,6 \mathrm{a}$ & $78,8 \mathrm{~b}$ & $75,1 \mathrm{~b}$ & $6,83 b$ \\
\hline 24 & $19.225,5 \mathrm{a}$ & $4.865,1 \mathrm{a}$ & $27,4 \mathrm{a}$ & $16,5 \mathrm{a}$ & $207,3 \mathrm{a}$ & $82,2 \mathrm{a}$ & $85,2 \mathrm{a}$ & $7,73 a$ \\
\hline 25 & $18.391,2 \mathrm{a}$ & $6.055,7 \mathrm{a}$ & $32,3 \mathrm{a}$ & $15,3 \mathrm{a}$ & $167,9 \mathrm{a}$ & $79,2 b$ & $74,7 \mathrm{~b}$ & $7,30 \mathrm{a}$ \\
\hline 26 & $23.916,7 \mathrm{a}$ & $6.809,0 \mathrm{a}$ & $28,5 \mathrm{a}$ & $15,2 \mathrm{a}$ & $192,3 \mathrm{a}$ & $88,6 \mathrm{a}$ & $82,0 \mathrm{a}$ & $7,73 a$ \\
\hline $\mathrm{T} 1$ & $18.482,9 \mathrm{a}$ & $5.423,6 \mathrm{a}$ & $28,8 \mathrm{a}$ & $13,1 b$ & $177,1 \mathrm{a}$ & $85,0 \mathrm{a}$ & $80,2 \mathrm{a}$ & $7,00 \mathrm{a}$ \\
\hline $\mathrm{T} 2$ & $22.751,4 \mathrm{a}$ & $7.327,0 \mathrm{a}$ & $32,1 \mathrm{a}$ & $12,5 \mathrm{~b}$ & $170,9 \mathrm{a}$ & $84,8 \mathrm{a}$ & $78,6 \mathrm{a}$ & $7,10 \mathrm{a}$ \\
\hline $\mathrm{T} 3$ & $23.285,8 \mathrm{a}$ & $7.491,4 \mathrm{a}$ & $31,8 \mathrm{a}$ & $13,3 b$ & $210,1 \mathrm{a}$ & $91,7 \mathrm{a}$ & $81,9 \mathrm{a}$ & $7,63 a$ \\
\hline $\mathrm{T} 4$ & $18.436,1 \mathrm{a}$ & $6.715,6 \mathrm{a}$ & $36,4 \mathrm{a}$ & $13,1 \mathrm{~b}$ & $179,6 \mathrm{a}$ & $86,3 \mathrm{a}$ & $80,2 \mathrm{a}$ & $7,93 \mathrm{a}$ \\
\hline Média geral & $14.432,1$ & $4.693,2$ & 32,8 & 14,6 & 159,5 & 77,1 & 74,1 & 7,01 \\
\hline
\end{tabular}

${ }^{(1)}$ Médias seguidas de letras iguais pertencem ao mesmo grupo, de acordo com o teste de Scott Knott, a 5\% de probabilidade. ${ }^{(2)} \mathrm{De} 1$ a 26 , famílias de irmãos completos; T1, 'BRS Sol do Cerrado'; T2, 'BRS Gigante Amarelo'; T3, 'BRS Ouro Vermelho'; e T4, 'FB 200'.

\section{Conclusões}

1. A inclusão de variedades comerciais de maracujazeiro-amarelo, a serem utilizadas na seleção recorrente em população inicial com baixa variabilidade genética, proporciona altos valores das médias das características e dos parâmetros genéticos avaliados, nos genótipos selecionados.

2. O uso do índice de seleção de Mulamba \& Mock proporciona ganhos genéticos positivos em produtividade, percentagem e peso de polpa, comprimento, diâmetro e peso de fruto, e espessura de casca.

\section{Agradecimentos}

À Cooperativa Agropecuária Mista Terra Nova, pelo apoio financeiro.

\section{Referências}

AGRIANUAL: anuário estatístico da agricultura brasileira. São Paulo: FNP Consultoria e Comércio, 2010. 520p.

COMSTOCK, R.E.; ROBINSON, H.F. The components of genetic variance in populations of biparental progenies and their use in estimating the average degree of dominance. Biometrics, v.4, p.254-266, 1948. 
CRUZ, C.D. Programa Genes: aplicativo computacional em genética e estatística. Viçosa: UFV, 2006a. 648p.

CRUZ, C.D. Programa Genes: biometria. Viçosa: UFV, 2006b. $382 \mathrm{p}$.

CRUZ, C.D.; CARNEIRO, P.C.S. Modelos biométricos aplicados ao melhoramento genético. Viçosa: UFV, 2003. v.2, 585p.

CRUZ, C.D.; REGAZZI, A.J.; CARNEIRO, P.C.S. Modelos biométricos aplicados ao melhoramento genético. 3.ed. Viçosa: UFV, 2004. v.1, 480p.

GONÇALVES, G.M.; VIANA, A.P.; BEZERRA NETO, F.V.; PEREIRA, M.G.; PEREIRA, T.N.S. Seleção e herdabilidade na predição de ganhos genéticos em maracujá-amarelo. Pesquisa Agropecuária Brasileira, v.42, p.193-198, 2007.

HALLAUER, A.R. Recurrent selection in maize. Advanced Agronomy, v.102, p.115-179, 1992.

HALLAUER, A.R.; DARRAH, L.L. Compendium of recurrent selection methods and their application. Critical Reviews in Plant Science, v.3, p.1-34, 1985.

JUNQUEIRA,N.T.V.;ICUMA,I.M.;VERAS,M.C.M.;OLIVEIRA, M.A.S.; ANJOS, J.R.N. dos. Cultura do maracujazeiro. In: SILVA, J.M. de M. (Ed.). Incentivo a fruticultura no Distrito Federal: manual de fruticultura. Brasília: Coolabora, 1999. p.42-52.

MORAES, M.C. de; GERALDI, I.O.; MATTA, F. de P.; VIEIRA, M.L.C. Genetic and phenotypic parameter estimates for yield and fruit quality traits from a single wide cross in yellow passion fruit. HortScience, v.40, p.1978-1981, 2005.

MULAMBA, N.N.; MOCK, J.J. Improvement of yield potential of the Eto Blanco maize (Zea mays L.) population by breeding for plant traits. Egyptian Journal of Genetics and Cytology, v.7, p.40-51, 1978.

NEGREIROS, J.R. da S.; BRUCKNER, C.H.; CRUZ, C.D.; SIQUEIRA, D.L. de; PIMENTEL, L.D. Seleção de progênies de maracujazeiro-amarelo vigorosas e resistentes à verrugose. Revista Brasileira de Fruticultura, v.26, p.272-275, 2004.
OLIVEIRA,E.J.de;SANTOS,V.daS.;LIMA,D.S.de;MACHADO, M.D.; LUCENA, R.S.; MOTTA, T.B.N.; CASTELLEN, M.S. Seleção em progênies de maracujazeiro-amarelo com base em índices multivariados. Pesquisa Agropecuária Brasileira, v.43, p.1543-1549, 2008.

PAULA, R.C. de; PIRES, I.E.; BORGES, R. de C.G.; CRUZ, C.D. Predição de ganhos genéticos em melhoramento florestal. Pesquisa Agropecuária Brasileira, v.37, p.159-165, 2002.

RAMALHO, M.A.P.; ABREU, A. de F.B.; SANTOS, J.B. dos. Genetic progress after four cycles of recurrent selection for yield and grain traits in common bean. Euphytica, v.144, p.23-29, 2005.

SANTOS, C.E.M. dos; PISSIONI, L.L.M.; MORGADO, M.A.D.; CRUZ, C.D.; BRUCKNER, C.H. Estratégias de seleção em progênies de maracujazeiro-amarelo quanto ao vigor e incidência de verrugose. Revista Brasileira de Fruticultura, v.30, p.444-449, 2008.

SCOTT, A.J.; KNOTT, M. A cluster analysis method for grouping means in the analysis of variance. Biometrics, v.30, p.507-512, 1974.

SILVA, M.G. de M.; VIANA, A.P.; GONÇALVES, G.M.; AMARAL JÚNIOR, A.T. do; PEREIRA, M.G. Seleção recorrente intrapopulacional no maracujazeiro amarelo: alternativa de capitalização de ganhos genéticos. Ciência e Agrotecnologia, v.33, p.170-176, 2009.

VIANA, A.P.; PEREIRA, T.N.S.; PEREIRA, M.G.; SOUZA, M.M. de; MALDONADO, J.F.M.; AMARAL JÚNIOR, A.T. do. Diversidade genética entre genótipos comerciais de maracujazeiro-amarelo (Passiflora edulis f. flavicarpa) e entre espécies de passifloras nativas determinada por marcadores RAPD. Revista Brasileira de Fruticultura, v.25, p.489-493, 2003.

VIANA, A.P.; PEREIRA, T.N.S.; PEREIRA, M.G.; SOUZA, M.M. de; MALDONADO, J.F.M.; AMARAL JÚNIOR, A.T. do. Genetic diversity in yellow passion fruit populations. Crop Breeding and Applied Biotechnology, v.6, p.87-94, 2006.

Recebido em 2 de março de 2011 e aprovado em 7 de dezembro de 2011 